\title{
Long-term effects of early ethanol on predatory behavior in inbred mice
}

\author{
JOSEPH YANAI and BENSON E. GINSBURG \\ Behavioral Genetics Laboratory, Department of Biobehavioral Sciences \\ The University of Connecticut, Storrs, Connecticut 06268
}

\begin{abstract}
A system was developed to study the long-lasting neurological and behavioral effects of known amounts of ethanol received transplacentally and via the mother's milk by $\mathrm{C} 57 \mathrm{BL} / 10$ and DBA/1 mice offspring. The present paper is concerned with the cricket-predation behavior of the offspring at ages 50 and 51 days. Treated DBA offspring had a $58 \%$ reduction in predatory incidences, compared to control, but the already nonpredatory C57 strain was not affected significantly by ethanol. The treated mice that preyed on the crickets had normal latencies. A few general facts related to the nature of predatory behavior were also noticed: DBA mice had a higher proportion of predation and shorter latencies than C57, improvement across trials was specific to the C57 strain, there was a high correlation between trials, both sexes displayed predatory behavior, and isolation did not affect predation. Predatory behavior offers a simple reliable tool for psychopharmacological research.
\end{abstract}

Predatory behavior of laboratory rodents has been studied mainly in rats. It is well known that the laboratory rat will kill and consume mice (Muricide; Karli, 1956), frogs (Ranacide), chicks, turtles, and cockroaches (Bandler \& Moyer, 1970).

Studies of the stomach contents in feral mice revealed that the mouse (Mus musculus) is actually an omnivore, as 30\% of its diet consists of insects (Calhoun, 1941; Whitaker, 1966). The insect predatory behavior of the feral and the laboratory mouse was later demonstrated under experimental conditions, and the effects of genotype, experience, and sex were assessed (Butler, 1973; Thomas, 1969; Newell \& Wilson, Note 1).

A system was developed recently demonstrating the effect of early ethanol input (pre- and postnatal) to induce long-lasting behavioral, neural, and metabolic changes. Early administration of ethanol resulted in an increased susceptibility to audiogenic seizures, a decrease in open-field activity (Yanai \& Ginsburg, 1973), and a decrease in male agonistic behavior (Yanai, Ginsburg, \& Vinopal, 1976). The serotonergic system was implicated as a possible mediator of the changes in seizure behavior (Yanai et al., 1975). The activity of ethanol metabolizing enzymes was also affected by early ethanol (Sze, Yanai, $\&$ Ginsburg, 1976). Since it is clear that aggression is not a unitary concept (Moyer, 1968), it seems useful to compare the effect of early ethanol on mouse predatory behavior with its effect on agonistic behavior. Further study of this effect of pharmacological input (ethanol) during development on a simple, consistent, and highly instinctive behavior (predation) may provide a useful

This research was supported by USPHS Grants RR 00602 and AA 00297 and The Grant Foundation, Inc. J. Yanai's present address is: Department of Biological Sciences, Purdue University, West Lafayette, Indiana 47907. model for the study of the mechanism of such behavior and the action of early ethanol. Consequently, mice from two inbred strains, C57BL/10 and DBA/1, which are known to differ in their agonistic behavior (Ginsburg $\&$ Allee, 1942) were exposed to ethanol during early development. Their predatory behavior at an older age was assessed in relation to that of untreated controls. Since isolation induces aggression (Valzelli, 1969), the role of isolation in predatory behavior was also evaluated.

\section{METHOD}

Inbred C57BL/10/Bg (C57) and DBA/1/Bg (DBA) mice which were used as parents in the present experiment were weaned on Day 28. They were segregated by sex and housed four per cage (16.0 $\times 26.5 \times .11 .5 \mathrm{~cm}$ high) in standard clear Plexiglas cages containing wood shavings as bedding. Experimental animals were given mouse chow ad lib and tap water containing $10 \% \mathrm{v} / \mathrm{v}$ ethanol ad lib as their only liquid source. Control animals were given mouse chow and tap water, available ad lib. The animals were maintained under their respective conditions until 60 days of age, at which time they were bred to animals of the same strain and treatment. Pregnant females were housed individually and remained on this nutritional regimen until 14 days post parturition, when the alcohol solution was replaced by tap water; the offspring were never exposed directly to alcohol but received it only transplacentally and via the mother's milk. From the day of isolation until 10 days post parturition the female parents and their offspring were not handled. Later they were transferred once a week to a clean cage. At 28 days of age, the offspring which were the subjects for the experiment were segregated by sex and housed five per cage. Additional groups of C57 offspring were housed individually and were never handled. Sample sizes were 30 treated and 30 control in each strain and 20 isolated treated and 20 isolated control from the C57 strain only, thus bringing the total number of animals used to 160 . An equal number of males and females were kept in each group. At 49 days of age, the animals were housed individually in standard cages containing fine "Ab-Sorb-Dri" bedding. Those animals kept in isolation since weaning were also transferred to 
cages containing "Ab-Sorb-Dri." Testing began on the next day (50) and was repeated $24 \mathrm{~h}$ later.

In the test, an adult common cricket (Acheta domesticus) was dropped into the mouse home cage. The behavior of the mouse was observed until the cricket was killed or $1,800 \mathrm{sec}$ had elapsed. The latencies to the first attack and to the successful attack were recorded. "First attack" was carefully distinguished from sniffing or just touching the cricket; "successful attack" was defined as killing the cricket. The results are presented pooled across sexes and isolation or grouping conditions, since these variables had no effect on predatory behavior.

\section{RESULTS}

Daily ethanol intake by the parents and the resulting blood ethanol levels were studied extensively and will be published elsewhere. Briefly, parents consumed $10-15 \mathrm{~g}$ ethanol $/ \mathrm{kg}$ body weight/day at mating age and $12-28 \mathrm{~g} / \mathrm{kg} /$ day during nursing (females). The blood ethanol levels during mating age were $2045 \mathrm{mg}$ percent at the dark hours and essentially zero during the day. The physical development of the ethanol drinking parents and their offspring was generally normal.

The percent of offspring which attacked at least once during the two test days and the percent of offspring with further attacks until the cricket was killed are presented in Table 1 . While 22 out of the 30 control DBA attacked and 19 killed the crickets, only 10 out of the 30 early ethanol-treated DBA attacked, and 9 killed, the cricket $(\mathrm{p}<.01)$. Control C57 mice had low predation scores; thus, early ethanol treatment caused only a small, and not a statistically significant, reduction in the predation scores of this strain. The latencies to attack and to successful attack of the mice who preyed on the crickets were similar in the ethanol and control groups.

Table 2 presents the latencies to successful attack across strains and trials (ethanol and control were pooled as there was no treatment effect). DBA mice had $65 \%$ shorter latencies than C57 on the first trial ( $p<.001)$, but the differences diminished on the second trial ( $p<.001$ for Strain by Trial interaction). There were significant correlations of $r=.6-.8$ between trials for attack and successful attack $(\mathrm{p}<.001)$. In latencies, however, only C57 had significant correlations $(r=.4-.7$;

Table 1

Percent of Ethanol Treated and Control Offspring Displaying Predatory Behavior

\begin{tabular}{clcc}
\hline Strain & (Sample Size) & $\begin{array}{c}\text { Percent } \\
\text { Attack }\end{array}$ & $\begin{array}{c}\text { Percent } \\
\text { Successful } \\
\text { Attack }\end{array}$ \\
\hline \multirow{2}{*}{ C57BL } & Control (50) & 38 & 32 \\
& EtOH (50) & 26 & 18 \\
\multirow{2}{*}{ DBA } & Control (30) & $73 \dagger \dagger$ & $63+\dagger$ \\
& EtOH (30) & $33^{* *}$ & $27^{* *}$ \\
\hline
\end{tabular}

** or $\dagger \dagger p<.01$. (Test of the difference between proportions; Npq, Arkin \& Colton, 1970)

**Deviation from control levels

$\dagger \dagger$ Strain differences within treatment
Table 2

Strain and Trial Comparisons of the Latency (in Seconds) to Successful Attack

\begin{tabular}{cccc}
\hline Strain & (Sample Size) & Trial 1 & \multicolumn{1}{c}{ Trial 2 } \\
\hline C57 & $(25)$ & $1114 \pm 139$ & $449 \pm 87$ \\
DBA & $(27)$ & $396 \pm 122$ & $428 \pm 129$ \\
\hline
\end{tabular}

Note- $p<.001$ for the Trial effect in C57 and for Strain by Trial interaction (2-way ANOVA repeated measure design). Scores are means $\pm S E M$ of animals which killed at least one cricket.

$\mathrm{p}<.01)$; DBA correlations did not reach a level of significance.

\section{DISCUSSION}

Early ethanol input in mice induced long-term physiological changes (probably neural) which resulted in long-term reduction in predatory behavior. Mice whose parents consumed ethanol during pregnancy and the first 14 days of nursing were less likely to become predators; however, those that preyed displayed a normal predatory behavior. In the highly predatory DBA strain, predation was decreased in the treated group to the level of the less predatory C57. The C57 strain normally has a low predation score; thus, the ethanol treatment did not reduce it significantly.

The significance of the present finding, as well as of our previous findings on seizure, open-field, and agonistic behavior, is in demonstrating that when a psychotropic drug such as ethanol is given in very small amounts (in terms of blood levels) during the stage of early development, when the nervous system is still susceptible to changes, long-term impairment of function may be produced. Unlike the case of an input to adults, there would be no recovery of function, even in behaviors of a great functional value (Yanai \& Ginsburg, 1973; Yanai et al., 1976).

Comparison of the rat's mouse-killing behavior to the pattern of the mouse's predatory behavior in the present and other experiments reveals some similarities. As in the cricket killing of the mouse, some rats will kill a mouse upon first exposure and will continue to do so, while nonkillers usually remain so, even after repeated exposure to mice (Karli, 1956). The behavior can be elicited without prior food deprivation or isolation (Myer, 1969) and in both sexes (Paul, Miley, \& Baenninger, 1971). As in mice, some of the differences between strains of rats are probably genetically determined (Karli, Vergnes, \& Didergeorges, 1969). Unlike mouse killing by rats, where the question of whether or not it is predatory is still open (King \& Hoebel, 1968), the killing of crickets by mice is most likely predatory since their natural diet contains insects (Whitaker, 1966). Although mouse predatory behavior is modified by ethanol as agonistic behavior similarly is (Yanai et al., 1976), the two behaviors are not the same; unlike agonistic behavior, both sexes attack crickets and isolation does not increase predation. 
Although our previous studies have demonstrated that the offspring whose parents were fed ethanol sustained a relatively normal development, it may be argued that the behavioral changes following early ethanol input actually resulted from early malnutrition due to a replacement of protein by ethanol in the diet. Assessment of the relative contribution of the direct effect of ethanol and its possible indirect effect via malnutrition is the subject of a current investigation. Thus far, it has been demonstrated that changes in the susceptibility to audiogenic seizure and male agonistic behavior following early exposure to ethanol are a direct result of ethanol not mediated by nutritional factors. Although agonistic and predatory behaviors are to some extent related, further studies are necessary to eliminate the possibility of nutritional interactions with the direct ethanol effects on predatory behavior.

A secondary, yet interesting finding of the present experiment was that a higher proportion of $\mathrm{DBA} / 1$ mice attacked and killed crickets as compared to C57BL/10 mice. The DBAs' latencies were also shorter. These results are consistent with those of Newell and Wilson (Note 1) on DBA/2Crgl and C57BL/6Crgl, but not with those of Butler (1973), who rated DBA/2Crgl less predatory than $\mathrm{C} 57 \mathrm{BL} / \mathrm{Crgl}$. Investigation of possible environmental or experimental variables that were powerful enough to reverse the results are of potential interest for the understanding of the behavior concerned. It is also worth noticing that improvement in predation speed across trials is genetically determined, since only C57 attacked and killed faster on the second day. The latencies of C57 mice on the second day matched those of the DBAs. The lack of an experience effect on DBA may be explained by the fact that they performed well from the first trial, which leaves less room for improvement. A trial effect was also demonstrated by Butler (1973), but not by Newell and Wilson (Note 1).

Male agonistic behavior is used routinely in psychopharmacological research (Janssen, Jageneau, \& Neimegeers, 1960). It is suggested that the mouse's predatory behavior is even better suited for the same purpose. Unlike agonistic behavior, this is a simple, "one-way" behavior where every mouse produces a score, both sexes can be utilized, no isolation is necessary, and treatment effects can be revealed even after one trial. The test is consistent and offers variability and interactions between genotypes for response to drug and experience.

Neuropharmacological studies on the effect of early ethanol input on the susceptibility to audiogenic seizure have implicated the serotonergic system as mediating the behavioral changes, probably with the adrenal glucocorticoid as a required factor (Sze, Yanai, \& Ginsburg, 1974; Yanai, Sze, \& Ginsburg, 1975). Similarly, neurochemical or neuropharmacological studies at the sensitive period for the ethanol effect on predatory behavior or during the testing age may further facilitate the understanding of ethanol effect on behavior and of the mechanism of the behavior concerned.

\section{REFERENCE NOTE}

1. Newell, T. G., \& Wilson, G. The predatory mouse: A genetic analysis. Paper presented at the Second Annual Meeting of the Behavior Genetics Association, Boulder, Colorado, 1972.

\section{REFERENCES}

Arkin, H., \& Colton, R. R. Statistical methods. New York: Barnes \& Noble, 1970.

BANDLER, R. J., \& MoYeR, K. E. Animals spontaneously attacked by rats. Communications in Behavioral Biology, 1970, 5, 177-182.

ButLeR, K. Predatory behavior in laboratory mice: Strain and sex comparisons. Journal of Comparative and Physiological Psychology, 1973, 85, 243-249.

Calmoun, J. B. Distribution and food habits of mammals in the vicinity of the Reelfoot Lake Biological Station. Journal of the Tennessee Academy of Science, 1941, 16. 207-225.

Ginsburg, B. E., \& Allee, W. C. Some effect of conditioning of social dominance and subordination in inbred strains of mice. Physiological Zoology, 1942, 15, 485-506.

JansSen, P. A., Jageneau, A. H., \& Neimegeers, C. J. E. Effects of various drugs on isolation-induced fighting behavior of male mice. Journal of Pharmacology and Experimental Therapeutics, 1960, 129, 471-475.

KARLI, P. The Norway rat's killing response to the white mouse: An experimental analysis. Behaviour, 1956, 10, 81-103.

Karli, P., Vergnes, M., \& Didergeorges, F. Rat mouse interspecific aggressive behavior and its manipulation by brain ablation and by brain stimulation. In S. Garattini \& E. B. Sigg (Eds.), Aggressive behaviour. Amsterdam: Excerpta Medica Foundation, 1969.

King, M. B., \& Hoebel, B. G. Killing elicited by brain stimulation in rats. Communications in Behavioral Biology, 1968, 2, 173-177.

MoYer, K. E. Kinds of aggression and their physiological basis. Communications in Behavioral Biology, 1968, 2, 65-87.

MYER, J. S. Early experience and the development of mouse killing by rats. Journal of Comparative and Physiological Psychology, 1969, 67, 46-49.

Paul, L., Miley, W. M., \& Baenninger, R. Mouse killing by rats: Role of hunger and thirst on its initiation and maintenance. Journal of Comparative and Physiological Psychology, 1971, 76, 242-249.

Sze, P. Y., Yanai, J., \& Ginsburg, B. E. Adrenal glucocorticoid as a required factor for the development of seizure in mice drinking ethanol. Brain Research, 1974, 80, 155-159.

Sze, P. Y., YanAI, J., \& Ginsburg, B. E. Effects of early ethanol input on the activities of ethanol metabolizing enzymes in mice. Biochemical Pharmacology, 1976, 25, 215-217.

Tномаs, K. Predatory behavior in two strains of laboratory mice. Psychonomic Science, 1969, 15, 13-14.

Valzelli, I. Aggressive behavior induced by isolation. In $S$. Garattini \& E. B. Sigg (Eds.), Aggressive behavior. New York: Wiley, 1969.

Whitaker, J. O. Food of Mus musculus, Peromyscus maniculatus bairdii and Peromyscus laucopus in Vigo County, Indiana. Journal of Mammalogy, 1966, 47, 473-486.

YANAI, J., \& Ginsburg, B. E. The effect of alcohol consumed by parent mice on the susceptibility to audiogenic seizure and the open-field behavior of their offspring. Behavior Genetics, 1973, $3,418$.

YANAI, J., Ginsburg, B. E., \& Vinopal, B. Comparison of early effects of ethanol on agonistic behavior in inbred strains of mice. Behavior Genetics, 1976, 6, 122-123.

Yanai, J., Sze, P. Y., \& Ginsburg, B. E. Effects of aminergic drugs and glutamic acid on audiogenic seizures induced by early exposure to ethanol. Epilepsia, 1975, 16, 67-72.

(Received for publication February 11, 1976; revision accepted July 8,1976 .) 